\title{
Equilibrium scour morphology downstream of rock sills under unsteady flow conditions.
}

\author{
Stefano Pagliara ${ }^{1, *}$, and Michele Palermo ${ }^{1}$ \\ ${ }^{1}$ DESTEC-Department of Energy, Systems, Territory and Construction Engineering, 56122 Pisa, Italy
}

\begin{abstract}
The present study aims to analyze the equilibrium scour morphology occurring downstream of rock-made sills with different shapes, under different inflow conditions. Namely, experimental tests were conducted under both steady and unsteady flow conditions. In this last case, the peak discharge was kept the same as the respective base tests performed for steady flow conditions. The scour evolution was carefully monitored, as well as the main characteristic lengths of the scour hole (e.g., maximum scour depth and axial length). The inflow discharge characteristics were varied, i.e., the maximum peak discharge was reached by adopting different hydrographs, in order to test their influence on the equilibrium morphology. Experimental results showed significant similitudes in terms of equilibrium scour morphology between steady and unsteady flow conditions when the hydrograph duration is enough long. The results of the present study can be useful for a correct design of such structure typology in usual applications.
\end{abstract}

\section{Introduction}

The analysis of scour mechanism downstream of grade-control structures is one of the most important topic for a river engineer. Grade-control structures are generally used to control sediment transport and at the same time they are able to create suitable conditions for fish species. Beside of the traditional concrete grade-control structures, low-environmental impact structures (e.g., block ramps, rock weirs, W-weir, J-hook, rock sills, etc.) have become more and more popular. This occurrence led scientists to develop strategies and find criteria to correctly design such type of structures under both clear water and live-bed conditions (for example, [1, 2, 3, 4, 5, 6]). In particular, hydraulic engineers' efforts aimed to understand the complex hydraulic functioning of structures made of stones and to provide relationships by which it could be possible to foresee the main lengths of the equilibrium scour morphologies (among others, [7, 8, 9, 10, 11, 12]). They showed that the scour geometry mainly depends on the following parameters: structure geometry, hydraulic conditions, channel bed configuration and stilling basin material. Furthermore, they showed that rock-structures generally determines advantages in terms of energy dissipation, i.e., the dissipative mechanisms are different from traditional concrete structures (e.g., dams or check dams, see $[13,14,15,16,17])$, resulting in an increase of the energy dissipation for identical hydraulic conditions. Nevertheless, all the mentioned studies are relative to steady

\footnotetext{
* Corresponding author: s.pagliara@ing.unipi.it
} 
flow conditions, i.e., to the authors' knowledge there is only one study [18] in literature dealing with the analysis of the scour mechanism under unsteady flow conditions in the presence of low-environmental impact structures. In [18], authors analysed both the maximum scour depth and its evolution, without focusing on the equilibrium morphologies. Therefore, the aim of the present paper is to discuss the equilibrium scour morphologies downstream of rock sills (both straight and arch-shaped), by putting in evidence the similitudes and differences characterizing the final scour configurations due to different unsteady flow conditions and steady flow conditions (i.e., under constant discharge equal to the peak discharge of the respective unsteady cases).

\section{Experimental set-up}

Experimental tests were conducted in a dedicated flume in which different rock sills were located. Namely, the adopted rock sills were made of crushed stones and shaped differently i.e., they were made of crushed stones $\left(D_{50}=4.56 \mathrm{~cm}\right)$ layers and shaped in such a way that the final configuration was either straight or arch-shaped. The channel bed material was uniform (non-uniformity coefficient $\sigma=1.22$ ) and characterized by a sediment density $\rho_{s}=2214 \mathrm{~kg} / \mathrm{m}^{3}$ ) and mean diameter $d_{50}=2 \mathrm{~mm}$. The curved rock sill was shaped in such a way that $R / B=0.5$, with $R$ curvature radius of the sill and $B$ the width of the channel. Figure 1 illustrates a diagram sketch of the tested structures along with the main geometric and hydraulic parameters. Namely, $h_{0}$ is the downstream water level, $z_{\max }$ is the maximum scour hole depth and $l_{s}$ the axial scour hole length. Figure 2 shows a picture of the arch-shaped rock sill adopted in the present study.
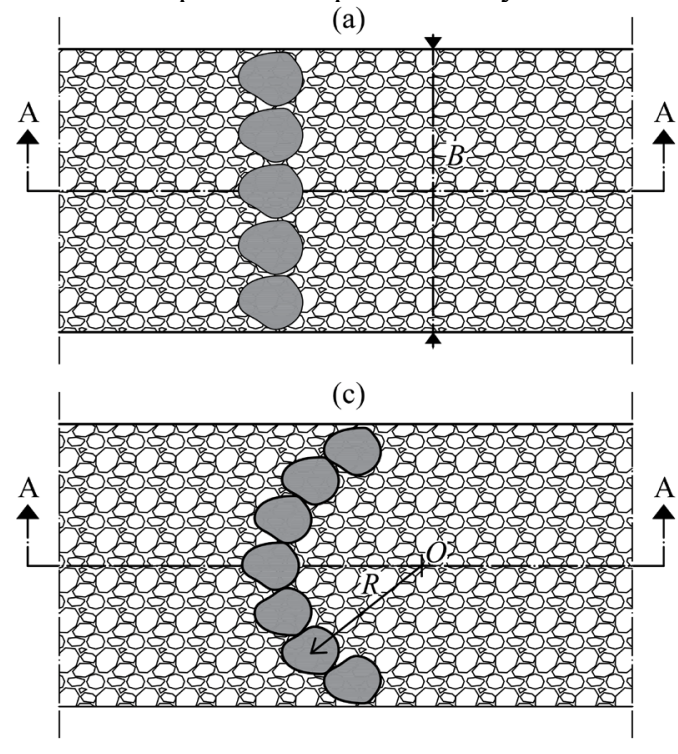

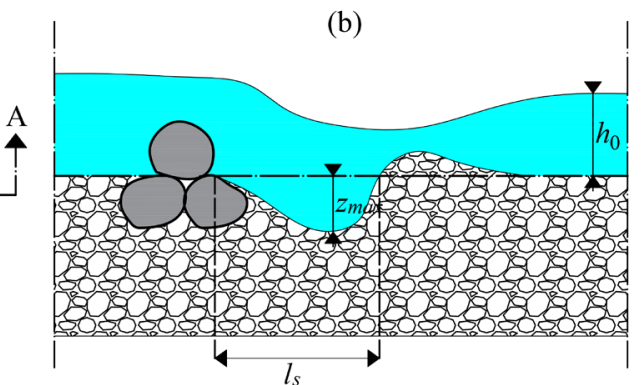

(d)

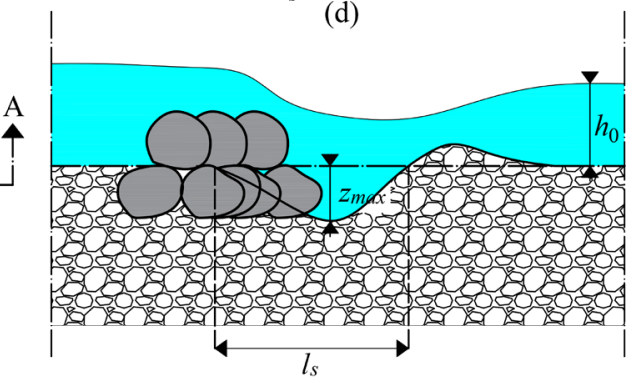

Fig. 1. Diagram sketch of a straight rock sill: (a) plan view, and (b) side view (section A-A). Diagram sketch of a curved rock sill: (c) plan view, and (d) side view (section A-A). 


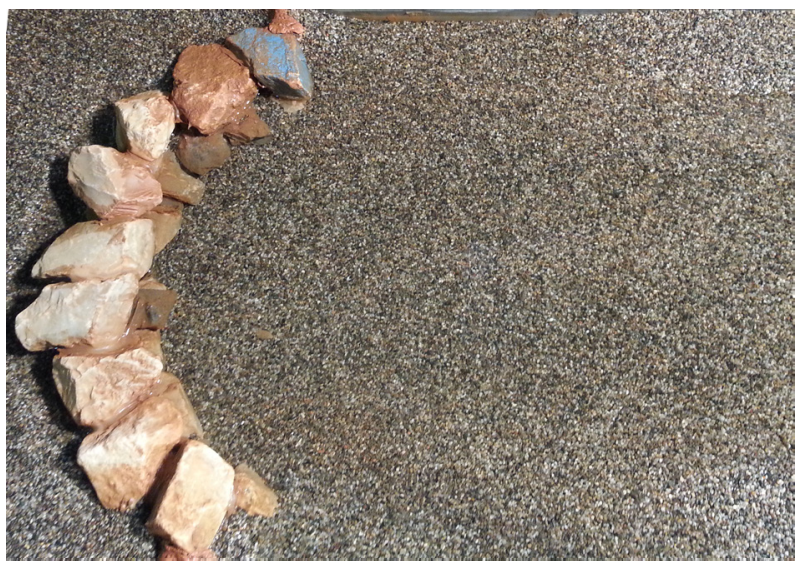

Fig. 2. Picture of the tested curved rock sill (flow from left to right)

For both the structures, preliminary experimental tests were conducted by keeping the discharge constant. In particular, two different discharge were tested, i.e, $Q=10 \mathrm{l} / \mathrm{s}$ and $151 / \mathrm{s}$. These preliminary tests allowed to obtain the reference value of $z_{\max }$ and $l_{s}$, as well as the equilibrium morphologies, under steady flow conditions. Once reference tests had been performed, experiments were repeated by varying the inflow conditions, i.e., under unsteady flow conditions, keeping the peak discharge $Q_{p}$ equal to that of the corresponding reference base tests $Q$. This methodology allowed for a direct comparison of the obtained equilibrium morphologies revealing both the similitudes and differences due to different inflow conditions. The inflow conditions were simulated by steps, varying the duration $\Delta t$ of each discharge increment $\Delta Q$, which was fixed equal to $1 \mathrm{l} / \mathrm{s}$. In particular, for this study $\Delta t$ ranged between $1 \mathrm{~min}$ and $12 \mathrm{~min}$, i.e., $\Delta t$ was set at $1,3,5,6,8$, and $12 \mathrm{~min}$, where $\Delta t_{\min }=1$ min simulates and almost continuous discharge variation. In other words, for each $i$ step, the discharge $Q(t)$ was kept constant for a duration equal to $n \Delta t_{\min }$, according to the selected step increment duration $\Delta t$, where $n$ is an integer varying between 1 and 12 .

Furthermore, the simulated inflow hydrograph was characterized by an increasing phase whose duration was half of the decreasing phase. Therefore, being constant $\Delta t$ in each test, the discharge decrement in the descending phase was set at $0.5 \Delta Q=0.5 \mathrm{l} / \mathrm{s}$. This choice well represents the usual inflow conditions characterizing natural streams. Figure 3 reports an example of a simulated hydrograph, in which $\Delta Q=1 \mathrm{l} / \mathrm{s}$ and $\Delta t=8 \Delta t_{\min }=8 \mathrm{~min}$. Therefore, for $Q_{p}=10 \mathrm{l} / \mathrm{s}$, we have 10 discharge increasing steps and 20 discharge decreasing steps, respectively. Whereas for $Q_{p}=15 \mathrm{l} / \mathrm{s}$, the increasing steps were 15 and the decreasing ones 30.

In each test, the scour evolution was carefully surveyed. The main geometric characteristics of the longitudinal scour profiles $\left(z_{\max }(t)\right.$ and $\left.l_{s}(t)\right)$ were collected at each instant $t$ by using a CCD camera and high definition images. The CCD camera was located orthogonally to the side glass wall of the channel, on which a plastic grid was glued to monitor the scour evolution (see [18] for details). Moreover, $z_{\max }(t)$ was measured by using a $0.1 \mathrm{~mm}$ precise point gauge fitted with a $10 \mathrm{~mm}$ circular plate at its lower end at selected instants. The combination of all the adopted measurements methodology allowed for a minimization of measurement errors. Therefore, the overall precision of the main scour hole parameters was of $\pm 1 \mathrm{~mm}$. 


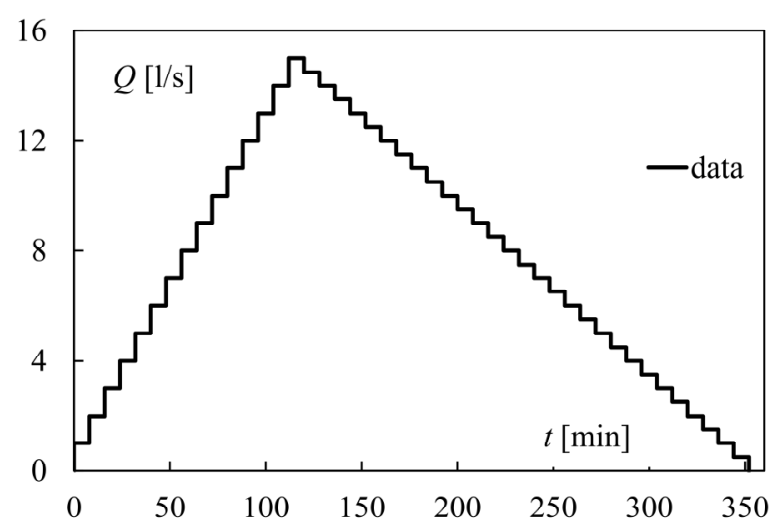

Fig. 3. Example of inflow hydrograph $(\Delta Q=11 / \mathrm{s}$ and $\Delta T=8 \mathrm{~min})$

\section{Results and discussion}

The analysis of the scour depth evolution was extensively conducted by [18]. In this paper, authors analyzed the relationships between $z_{\max }(t) / z_{\max }$ vs $Q(t) / Q_{\max }$, with $z_{\max }(t)$ the maximum scour depth value and $Q(t)$ the discharge at the instant $t$ from the test beginning. In particular, the comparison between different inflow conditions and test durations, was conducted by assuming two non-dimensional time scales, i.e., the non-dimensional interval duration $\Delta T$ relative to each discharge increment given by Eq. (1) and the non-dimensional time $T$ given by Eq. (2):

$$
\begin{array}{r}
\Delta T=\frac{\left[g\left(\left(\rho_{s}-\rho\right) / \rho\right) d_{50}\right]^{0.5} \Delta t}{k n} \\
T=\frac{\left[g\left(\left(\rho_{s}-\rho\right) / \rho\right) d_{50}\right]^{0.5} t}{k n}
\end{array}
$$

In previous equations, $g$ is the acceleration due to gravity and $k$ is the critical depth relative to the peak discharge $Q_{p}$, whereas, as mentioned above, $n$ is an integer varying from 1 to 12. Such non-dimensional interval duration and time results in a constant $\Delta T$ for unsteady flow tests characterized by the same $Q_{p}$, as in this case $k$ is constant and $\Delta t / n=\Delta t_{\text {min }}$. In addition, for steady flow tests (reference tests), $n$ can be assumed equal to 1 , as for $1 \Delta t=\Delta t_{\min }=1 \mathrm{~min}$ an almost continuous variation of the discharge occurs. Based on this assumptions, [18] observed that $z *_{\max } \approx z_{\max }$ for $n \geq 5$, where $z *_{\max }$ is the maximum scour depth in the corresponding unsteady flow test. In addition, [18] also analysed the non-dimensional temporal evolution of the variable $z_{\max }(t) / z_{\max }$, i.e., $z_{\max }(t) / z_{\max }$ vs $T$. They found that for $n \geq 5$ the evolution trend of the maximum scour depth is essentially the same for all tested configurations, i.e., the maximum scour depth occurring in unsteady flow tests is comparable to that of the corresponding steady test for $n \geq 5$. Finally, [18] introduced the variable $T_{p e a k}$, i.e., the non-dimensional time in which $Q_{p}$ occurs, calculated with Eq. (2), in which $k$ is the critical depth corresponding to $Q_{p}$ and $t=t_{p}$, i.e., the time when $Q_{p}$ occurs. For the selected inflow hydrograph shape and for all the tested conditions and configurations, $Q_{p}$ generally occurs for $2690<T_{\text {peak }}<4373$, i.e., $T_{\text {peak }}^{*} \approx 3200$ can be assumed as an average value. Based on these observations, [18] showed that for $n \geq 5$ and $T_{\text {peak }} \geq T_{\text {peak }}^{*} \approx 3200$ $z *_{\max } \approx z_{\max }$, i.e., the maximum scour depth does not depend on the inflow conditions if $Q=Q_{p}$. In other words, [18] furnished an explicit criterion to establish when equilibrium 
scour formulas can be adopted for unsteady flow conditions, without over-estimating the scour hole lengths. Nevertheless, the analysis and the results proposed by [18] does not furnish insights on the global equilibrium morphologies under different inflow conditions. Therefore, in the present paper, a more general and complete comparison between equilibrium scour characteristics is given, by comparing the equilibrium scour morphologies. In particular, Figure 4 shows the comparison between the equilibrium morphologies occurring under unsteady flow conditions (Figures 4a-c) and the corresponding under steady flow conditions, for tests with arch-shaped sill. More specifically, Figures $4 \mathrm{a}-\mathrm{c}$ report the equilibrium scour morphologies for unsteady tests in which $Q_{p}=10 \mathrm{l} / \mathrm{s}$ and $\Delta t=1 \Delta t_{\min }=1 \mathrm{~min}, \Delta t=6 \Delta t_{\min }=6 \mathrm{~min}$, and $\Delta t=8 \Delta t_{\min }=8 \mathrm{~min}$, respectively. Whereas, Figure $4 \mathrm{~d}$ shows the same for the reference steady test in which the discharge $Q$ was kept constant and equal to $Q_{p}$. The comparison between Figures 4a-c shows substantial differences in terms of final equilibrium morphologies. Namely, Figures $4 \mathrm{~b}$ and $4 \mathrm{c}$ put in evidence that for $\Delta t=6 \Delta t_{\min }$ and $\Delta t=8 \Delta t_{\min }$, the two equilibrium scour morphologies are characterized by essentially the same shape and same scour characteristic lengths (depth and length). Whereas, substantial differences can be pointed out by comparing Figures $4 \mathrm{~b}$ and $4 \mathrm{c}$ with Figure $4 \mathrm{a}$, relative to $\Delta t=\Delta t_{\min }$. Furthermore, the equilibrium morphology reported in Figure 4d, relative to steady flow conditions, exhibits clear similitudes with those obtained under unsteady flow conditions for $n \geq 5$, whereas it appears significantly different with respect to that shown in Figure $4 \mathrm{~b}(n=1)$. These occurrences confirm the findings of [18], i.e., not only the scour characteristics lengths are comparable, but also the global equilibrium morphologies are essentially the same for $n \geq 5$.
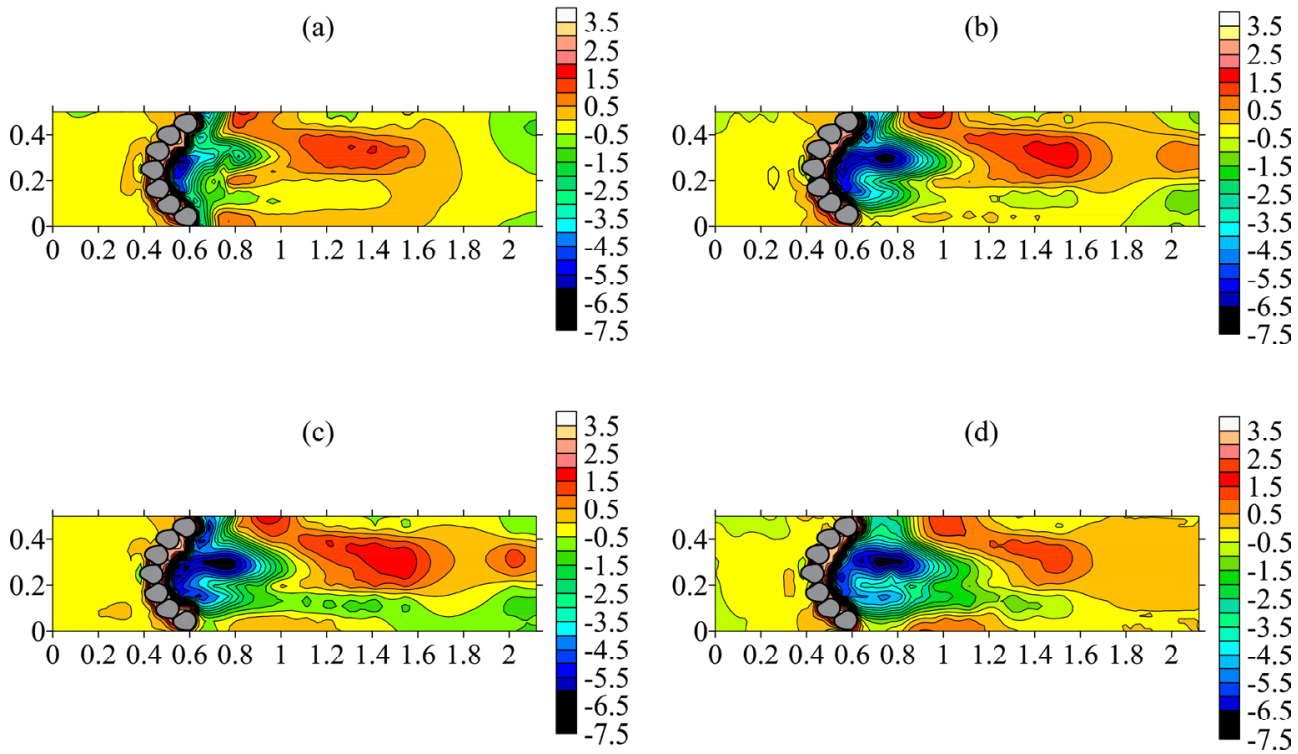

Fig. 4. Equilibrium scour morphologies for $\Delta Q=11 / \mathrm{s}$ and (a) $\Delta t=1 \Delta t_{\min }=1 \mathrm{~min}$, (b) $\Delta t=6 \Delta t_{\min }=6 \mathrm{~min}$, (c) $\Delta t=8 \Delta t_{\text {min }}=8 \mathrm{~min}$ and (d) for steady test with $Q=Q_{p}$

A similar analysis was conducted for equilibrium scour morphologies in the presence of straight sills, confirming and extending the findings of both [18] and of the present paper for arch-shaped sills. Figure 5 shows the comparison between the equilibrium morphologies occurring under unsteady flow conditions for tests with straight sills, where $Q_{p}=10 \mathrm{l} / \mathrm{s}$. More specifically, Figures $5 \mathrm{a}-\mathrm{b}$ report the $2 \mathrm{D}$ and $3 \mathrm{D}$ equilibrium morphology for a test in which $\Delta t=6 \Delta t_{\min }=6 \mathrm{~min}$, whereas Figures $5 \mathrm{c}-\mathrm{d}$ show the same for a test in which $\Delta t=8 \Delta t_{\min }=8 \mathrm{~min}$. It is worth noting that also in this case, the equilibrium morphologies, as 
well as the maximum scour depth and length are essentially the same for both the tests, thus confirming the general validity of the equilibrium morphology similitude for $n \geq 5$. This phenomenon is mainly due to the cyclical modelling of the stilling basin under unsteady flow conditions, resulting in the downstream ridge flattening during the hydrograph increasing phase. Therefore, the flow confinement exerted by the ridge partially vanishes, especially for lower $n$ values, modifying both scour evolution and equilibrium morphology. In terms of practical applications, both the findings of [18] and those presented in this manuscript assume a significant relevance, as they are related to usual conditions which can occur during flood events. More specifically, they imply that existing empirical and semitheoretical relationships valid for steady flow conditions can significantly over-estimate the maximum scour depth characteristics (up to approximately $40 \%$ in the tested range of parameters), especially in the usual case of unsteady flow conditions when $n<5$, i.e., typical conditions occurring in torrential streams. In addition, it can be concluded that if $T_{\text {peak }}>3200$, a substantial similitude between steady and unsteady tests occurs in terms of global equilibrium morphologies. In other words, by applying steady equilibrium equations, we always obtain conservative results in terms of maximum scour depth.

(a)

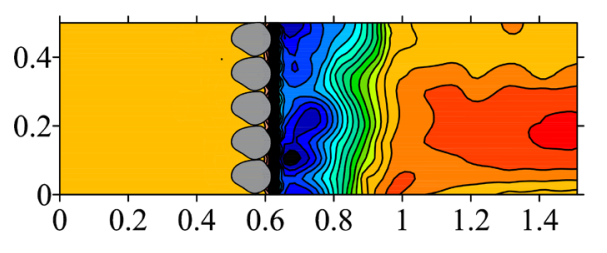

(c)

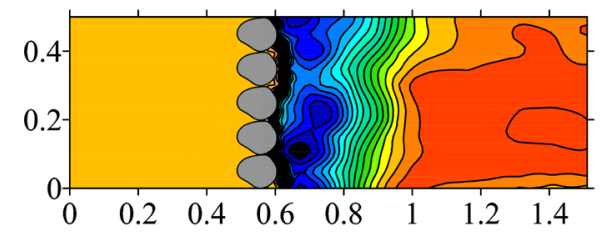

(b)

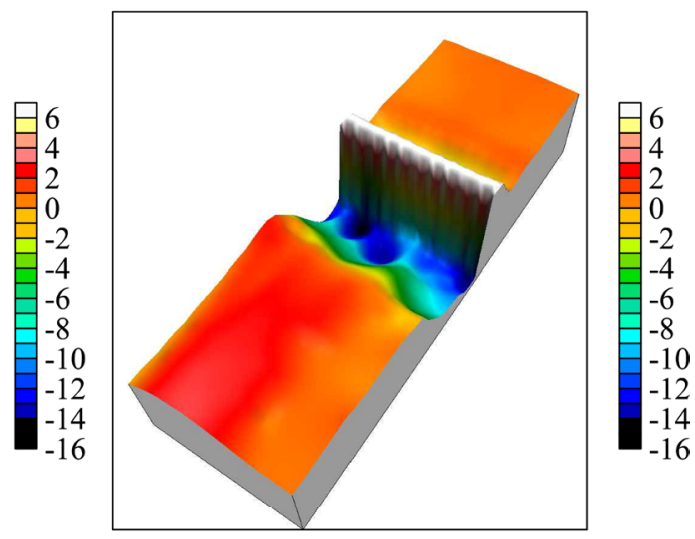

(d)

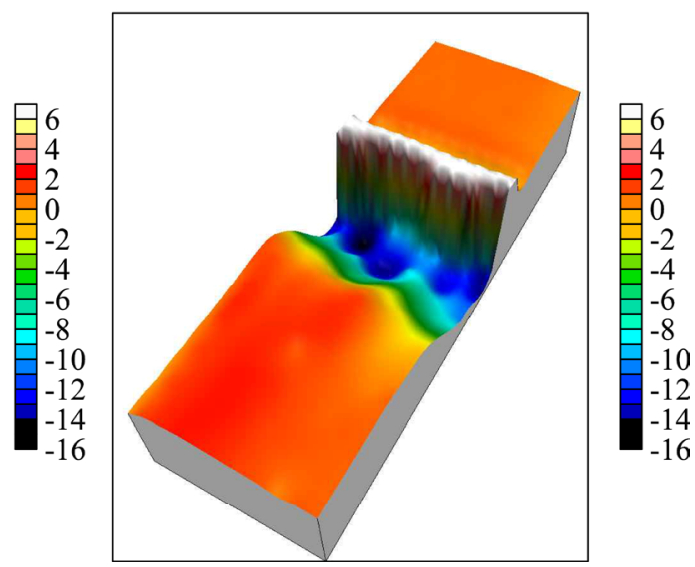

Fig. 5. $2 \mathrm{D}$ and $3 \mathrm{D}$ equilibrium scour morphologies for $\Delta Q=11 / \mathrm{s}$ and (a) and (b) $\Delta t=6 \Delta t_{\min }=6 \mathrm{~min}$, (c) and (d) $\Delta t=8 \Delta t_{\min }=8 \mathrm{~min}$, respectively 


\section{Conclusions}

In the present paper, equilibrium scour morphologies due to both steady and unsteady inflow conditions were compared and analyzed in the presence of two different rock sills (arch-shaped and straight, respectively). The aim of the present study was to validate and extend the findings of [18], relative to both the evolution dynamics of maximum scour depth and its value at equilibrium, to the global equilibrium morphology. In particular, it was found that substantial similitudes can be detected in terms of global equilibrium morphologies under both steady and unsteady inflow conditions when the peak discharge $Q_{p}$ occurs at a non-dimensional time $T$ bigger than 3200 . Conversely, the equilibrium scour morphologies due to either steady or unsteady flow conditions can be significantly different. In particular, for $n<5$, the scour morphology planar extension, as well as the maximum scour hole length and depth can be much smaller that the corresponding ones under steady flow conditions. This occurrence has a significant relevance in terms of practical applications and future researches. In fact, for $n<5$, it may result in a significant over-estimation of the maximum scour depth and length if calculated by using approaches valid for steady flow conditions. In other words, steady flow equations well predict scour characteristics and morphology only when the peak discharge under unsteady flow conditions occurs after a certain time, which can be evaluated by using the equation proposed by [18]. Vice versa, they are generally conservative. This last occurrence paths the way for future studies and developments. In fact, especially torrential streams, where such structure typology is generally located, are usually characterized by unsteady inflow hydrographs, whose duration is not enough long to guarantee a complete similitude in terms of equilibrium scour morphology with the corresponding one under steady flow conditions. Therefore, in this last case, the design criteria require to be optimized.

\section{References}

1. S. Pagliara, A. Radecki-Pawlik, M. Palermo, K. Plesinski, River Res. Appl., 33, 427437 (2017).

2. S. Pagliara, M. Palermo, J. Hydraul. Eng.-ASCE, 134, 1376-1382 (2008).

3. S. Pagliara, M. Palermo, J. Irrig. Drainage Eng-ASCE, 138, 1027-1031 (2012).

4. S. Pagliara, M. Palermo, J. Irrig. Drainage Eng-ASCE, 137, 593-601 (2011).

5. S. Pagliara, M. Palermo, I. Carnacina, Int. J. Sediment Res., 27, 337-350 (2012).

6. S. Pagliara, L. Hassanabadi, S. Mahmoudi Kurdistani, J. Irrig. Drainage Eng-ASCE, 141, 8 (2015).

7. E. Bormann, P.Y. Julien, J. Hydraul. Eng.-ASCE, 117, 579-594 (1991).

8. V. D’Agostino, V. Ferro, J. Hydraul. Eng.-ASCE, 130, 1-14 (2004).

9. S. Pagliara, M. Palermo, Acta Geophysica, 61, 126-150 (2013).

10. S. Pagliara, M. Palermo, J. Hydraul. Res., 53, 243-252 (2015).

11. M. Palermo, S. Pagliara, J. Hydro-environ. Res., 14, 150-156 (2017).

12. S. Pagliara, S. Mahmoudi Kurdistani, M. Palermo, D. Simoni, J. Hydro-environ. Res., 10, 12-20 (2016).

13. G.J.C.M. Hoffmans, J. Hydraul. Eng.-ASCE, 124, 430-437 (1998).

14. G.J.C.M. Hoffmans, J. Hydraul. Res., 136, 129-136 (2010).

15. S. Pagliara, S. Mahmoudi Kurdistani, Proceedings of the International Conference on Fluvial Hydraulics, RIVER FLOW 2014, 2093-2098 (2015).

16. A. Baki, D. Zhu, N. Rajaratnam, J. Hydraul. Eng., 140, 156-168 (2014).

17. L. Cassan, P. Laurens, Knowl. Manag. Aquat. Ecosyst., 417, 1-10 (2016).

18. M. Palermo, S. Pagliara, J. Hydro-environ. Res., (in press, DOI: 10.1016/j.jher.2017.04.001). 